\title{
Incorporating Seasonality into Agricultural Project Design and Learning
}

\author{
Stephen Devereux and Richard Longhurst
}

\begin{abstract}
Seasonality can be extremely damaging to the lives and livelihoods of rural people, but this is rarely recognised and factored into the design and implementation of agricultural projects. During the annual hungry season, farmers face empty granaries, high food prices and waterborne diseases, which compel them to adopt 'coping strategies' that perpetuate poverty ratchets. Seasonal employment programmes can smooth income and consumption but could overburden women, since seasonal workloads are highly gendered. Incorporating a seasonal perspective into agricultural programming requires building a seasonality assessment into the baseline survey and design phase of agricultural projects, reducing seasonal food insecurity by stabilising rather than maximising crop production, and enhancing seasonality awareness among agricultural advisers and project staff, in each local context. Incorporating seasonality into M\&E processes has implications for the timing and frequency of data collection, and requires a deeper understanding of the complexity of livelihood processes between and within rural households.
\end{abstract}

\begin{abstract}
1 Introduction
The potentially damaging consequences of seasonality for poor rural people - in terms of their crop and livestock production, employment, income, health and nutrition - have been well understood for decades (see Chambers et al. 1981; Gill 1991; Sahn 1989; Ulijaszek and Strickland 1993). Nonetheless, project designers and managers do not always give adequate attention to 'adverse seasonality', which raises fundamental issues for monitoring, evaluating and learning from agricultural projects to improve their design and outcomes. With this in mind, the research study on which this article is based asked three related questions.
\end{abstract}

1.1 Under which circumstances does seasonality create the greatest stress for farmers and farm households? Seasonality manifests differently in different contexts and the strategies that farmers adopt to cope with seasonality vary. However, studies of 'coping strategies' reveal common indicators of stress: selling food cheaply after harvest and buying it back later at high prices, rationing food consumption, even selling assets like livestock in severe 'hungry seasons'. These responses can undermine the viability of farm-based livelihoods. The design of agricultural projects can have positive or negative impacts on seasonal workloads (especially for women) and on the distribution of assets and income. How can agricultural projects reduce seasonal stress and minimise the forced adoption of damaging 'coping strategies?

\subsection{Why isn't seasonality acknowledged more in agricultural project design?}

Unirrigated agriculture is entirely dictated by seasonal cycles, but climate change is causing rainfall to become increasingly erratic, seasonal hunger to intensify and agriculture-based livelihoods to become increasingly vulnerable. Yet agricultural projects rarely recognise the centrality of seasonality in rural livelihoods. Why is seasonality neglected in project design and what are the implications for project outcomes and impacts?

\subsection{What are the key things that design can do differently?}

In many countries, agricultural policies were more sensitive to seasonality in the past than they are today. Governments in Africa and Asia 
Figure 1 Seasonality in rainfall, food prices and malnutrition in northern Ghana

(a) Rainfall

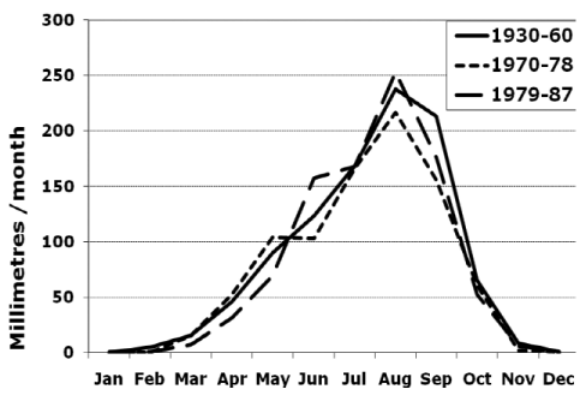

(c) Malnutrition

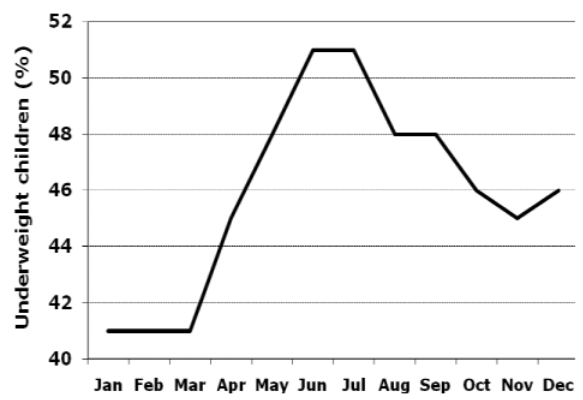

\section{(b) Millet prices}

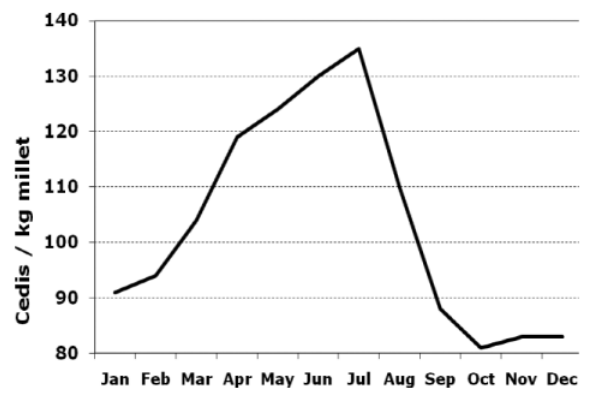

(d) Millet prices and malnutrition

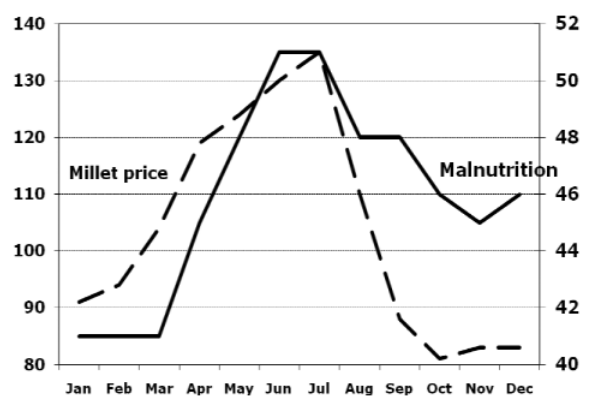

Source Devereux (2009: 5); reproduced with kind permission of the Future Agricultures Consortium.

administered counter-seasonal grain market operations, 'pan-seasonal' food pricing and subsidised input distribution. These interventions have largely disappeared, leaving poor farmers facing the challenges of seasonality with little protection. How can projects that support farmers be better designed to account for seasonal cycles in rainfall, production, labour requirements and employment opportunities, disease and malnutrition, and food and commodity prices?

\section{Consequences of seasonality}

'Adverse seasonality' is most severe for smallholder families that depend on a single unreliable source of livelihood - rainfed agriculture - in environments where rainfall is erratic and unpredictable. Especially in unimodal rainfall systems, the stresses that pronounced seasonality induces can compromise livelihoods and wellbeing, not just during the pre-harvest 'hungry season' but permanently. In much of rural Africa and Asia, farming families depend for their survival on a single annual harvest, but low-input, low-output agriculture results in seasonal food gaps, food price spikes, seasonal hunger and accumulated nutritional deficits that impair the physical and cognitive development of children.

Typically, grain prices in rural markets are lowest after the main harvest, when supplies are high and market demand is low. As on-farm granary stocks dwindle so demand from the market starts to rise, driving up prices especially in deep rural areas where markets are not well integrated. Prices peak in the rainy season, just before the next harvest. These trends in food supplies and prices have direct and measurable effects on household food security, as reflected in rates of malnutrition (see Figure 1, which illustrates the close correlation between rainfall, local grain prices and the prevalence of underweight children in northern Ghana).

A further complexity that agricultural projects should take into account is seasonal interactions between food availability and consumption, and human health conditions. The 'hungry season' is not only the time of year when food supplies are scarce and prices are high, it is also when waterrelated diseases (e.g. malaria, diarrhoea, cholera, typhoid) are most prevalent and unemployment is either scarce or under-remunerated due to 
over-supply of labour in areas where labour markets are weak.

The coincidence at specific times of year of sickness, undernutrition, and hard work on family farms generates a 'poverty ratchet', as hungry (and possibly unwell) farmers with empty granaries from last year's low-yielding harvests sell their assets at 'distress' prices to buy food.

The consequences for poverty can be quantified by undertaking household budget surveys in different seasons. In one panel survey of 1,400 rural Ethiopian households over 12 months, headcount poverty was lowest after the harvest, at 32 per cent, and highest during the preharvest months - at 39 per cent in 1994 and 41 per cent in 1995 (Dercon and Krishnan 2000).

The duration and severity of each season depends on the context. For instance, the range of food price variability between the harvest and 'hungry season' depends on whether there is one rainy season or two, the competitiveness and integration of local food markets, as well as food storage capacity and efficiency. Access to markets and services is also more constrained at certain times of year. If farmers cannot buy fertiliser or get their produce to market, or if mothers cannot take their children to clinics because of damaged roads, this inaccessibility contributes directly to seasonal hunger and ill-health.

In bimodal rainfall systems, the second rainy season allows a second planting and the two harvests are more likely to be sufficient to cover the family's food needs throughout the year. But even in these areas, farmers across the world are complaining that rainfall is becoming more erratic and unpredictable - a consequence of global climate change that is just as damaging for farmers as is lower total rainfall - and that this is affecting their planting decisions and harvests (Jennings and Magrath 2009). As Gaiha and Mathur argue in this IDS Bulletin, the rising frequency of droughts is disrupting existing seasonal patterns, and new agricultural technologies must be developed to counteract this.

If the overall objective of agricultural development is to reduce rural poverty, then a deeper understanding of these multi-faceted effects of seasonality must be factored into project design, implementation and evaluation for improved impact.

\section{How agricultural projects can counteract seasonality}

In many agricultural projects - for instance, crop breeding programmes that disseminate droughttolerant seeds - seasonality is central, at least implicitly, to conceptualisation and design. But even in these cases, the complexity of seasonality is rarely fully understood, and in others seasonality is entirely overlooked. Robert Chambers has explained this neglect in terms of differences between the lifestyles of development professionals and those of poor rural people.

'The perceptions and priorities of urban-based professionals, and the seasonality of their travel, campaigns and insights combine to hide seasonal deprivation and its integrated nature... Seasonproofed by their living environment, caught in urban traps, many professionals are season-blind' (Chambers 2009: 2).

Many agricultural interventions aim to enhance farmers' access to inputs that raise crop yields and harvests, such as 'high-yielding varieties' of seed (HYVs) or chemical fertilisers, in an effort to reduce seasonal food gaps and fluctuations in food availability - but this does not offset the risk of dependence on a single rainy season. A more appropriate response to seasonality is to develop water-stress tolerant varieties or to diversify production towards root crops, to provide some protection against agricultural droughts, and this has also been a focus of agricultural research strategies in many countries for many years.

Irrigation is another potentially effective counter-seasonal strategy, allowing for a second harvest and smoothing food availability through the year - which is more important where harvests are unpredictable than is raising average yields. But irrigation is not always ecologically or financially feasible - it needs significant, accessible water supplies and a topography that can sustain it. Alternatively, crop storage could be improved at the farm or community level, or cereal banks can be built to allow for seasonal purchases and resale within the village. A complementary strategy is to identify and promote secondary income sources, such as rural non-farm enterprises or public works employment, to generate non-agricultural incomes and diversify livelihood risk. Clearly, an integrated and locally contextualised approach is needed to address the negative impacts of agricultural seasonality. 
Our review of multilateral agency evaluation materials (Devereux and Longhurst 2010) found that irrigation, seasonal credit and improvement of rural infrastructure are the main approaches used to address seasonal production and consumption deficits. Sometimes, as in the case of irrigation, these interventions do not only address seasonal problems in the traditional 'hunger' season, but also try to develop more productive use of land in the dry season. The evaluations suggest that a range of projects and technologies is needed, tailored to the specific crops and resource endowments of farmers in each context. The issues faced in providing seasonal credit have long been recognised, along with the problem of transaction costs, which can be high in terms of addressing seasonal shortages. The agencies also addressed themselves to varying extents to challenges they have faced in supporting women (see below), who usually bear the brunt of seasonal deficits in food and income: often project resources applied to raise women's incomes do so at the cost of increasing their workload. There is a complex interaction between rural labour markets and farming and domestic labour requirements. The agency evaluation materials only occasionally address market wages, which are often depressed at the busiest times of year.

Our case study of vegetable production in Africa revealed that vegetables are important sources of both nutrition and income, but are relatively neglected by policymakers and agricultural researchers. Vegetables are subject to the same price seasonality as cereal crops, but because they have different cropping cycles they can provide counter-seasonal sources of food and income. The BMGF-supported Vegetable Breeding and Seed System (vBSS) project is disseminating improved varieties of indigenous and exotic vegetables, for higher yields, disease and drought resistance, and marketability. Farmers adopt improved varieties to increase household food consumption or to earn increased income from sales of produce. Since improved crops are more expensive to cultivate, they are more likely to be sold, while local crops are cheaper to cultivate and are more likely to be eaten by the family.

This raises a dilemma for project managers who are concerned with maximising impact: should they prioritise 'income for development' or 'consumption for food security'? Agricultural projects can address seasonality by boosting farmers' incomes (e.g. promoting production of high-value crops) or by boosting food consumption in farming families directly (e.g. promoting production of 'subsistence' crops). The former strategy might require targeting middle-income farmers (because commercial crop production requires a level of investment and risk-taking that is beyond the financial capacities of poor smallholders) and should achieve significant economic impacts, while the latter strategy is more likely to reach low-income farmers and should achieve greater impact on food security and nutrition.

Finally, effectively counteracting seasonality requires selective intervention in markets. Rural households that are worst affected by seasonal fluctuations in production, income and consumption must have access to new technologies and inputs, by strengthening delivery channels and providing subsidised credit. Seasonal employment for the rural landless or land deficit farmers can be beneficial, if it is well timed and sensitively designed. Technology can alter the income streams and workloads of people at seasonal peak periods. As farmers move towards a more commercial environment, there is an incremental exposure to market-related risk. Many poor farmers already buy and sell grain, labour and assets in different seasons at disadvantageous terms of trade. A better understanding is needed of how this 'terms of trade' problem can be alleviated, for instance through warehouse receipt systems or commodity warranty schemes, which protect farmers against seasonal price fluctuations.

\section{Gender and seasonality}

The review of agency evaluation materials showed mixed impacts on women in terms of their seasonal incomes and workloads. In IFADsupported work in Papua New Guinea, mothers faced severe time constraints in terms of time needed for childcare, for breast-feeding and for preparing meals. Time pressures on women are exacerbated in the peak agricultural season but are severe even during non-peak seasons. Tradeoffs between work commitments and childcare responsibilities can impact negatively on the nutritional status of children. Ambiguous outcomes can result when interventions reduce seasonal underemployment by providing work 
specifically for women (e.g. gender quotas on public works projects) - women can find themselves busier than ever, with multiple onfarm and off-farm activities demanding their time in different seasons.

Generally, agency experience showed that the effects of project activities on workloads have sometimes been negative for women but are usually positive for children. Improved water supplies in several projects reduced the burden of water collection on women and children, while time tending livestock has increased for children and men. The introduction of new production techniques in Benin overburdened women, given their lack of access to appropriate equipment, and they reportedly obtained little advantage, as their workload increased due to their work on erosion control sites. Instead, women (when asked) requested assistance to reduce their domestic drudge work such as water collection, which is also harder during the dry season than in the rains.

Project design should recognise the gender dimensions of seasonal workloads, agricultural production tasks and income-generating opportunities - recognising that responsibilities for providing for household food consumption are also highly gendered. Any agency wishing to ensure that income generation at the farm level is translated into significant improvements in nutrition of vulnerable groups (such as women and children) must address the gendered nature of seasonality in these sectors. In this context, there has been some success in developing communitybased organisations (CBOs) for women which can enhance literacy, their role in local decisionmaking and generating independent incomes, while taking note of the impact on seasonal workloads. Giving voice to people adversely affected by seasonality is an essential first step to eradicating its worst consequences.

\section{Factoring seasonality into agricultural programmes}

We have seen that seasonality has differential impacts on different groups of people, who have varying ability to manage seasonal risk. The rural poor and women are usually worst affected. Seasonality therefore has a dimension of power relations, insofar as some gain at the expense of others - a 'distress sale' of assets or labour by one person is a 'bargain buy' by another. A seasonal perspective is one that shows how agricultural production, income, market prices and nutritional status are interlinked, and incorporates the implications of these linkages into all interventions aimed at addressing rural poverty. On the face of it, therefore, recognising the effects of seasonality may appear to put extra demands on processes of monitoring, evaluation and subsequent learning, but we would argue that any extra costs of data collection and information sharing are more than balanced by the benefits this brings. Three steps are proposed: assessing, planning and designing for seasonality.

\subsection{Assessing for seasonality}

The first step is routinely to incorporate a 'seasonality assessment' into the baseline survey and design phase of all agricultural projects. This is important because often baseline surveys are carried out in the dry season, for logistical reasons: roads and bridges are not washed away, and it is easier to meet families in their houses. A 'seasonality assessment' requires generating a fairly detailed understanding - using participatory methods as were pioneered by Participatory Poverty Assessments (PPAs) during the 1990s - of how lives and livelihoods of local people are affected by seasonal cycles - in rainfall, production, employment, prices, health, nutrition, etc. - and the responses that farmers and others adopt to protect themselves against the worst consequences of these multiple dimensions of seasonality. The opening move - often ignored in assessments and surveys - is to ask whether there are problems of a 'hunger season'.

A 'seasonality assessment' should also be applied to existing sources of data. The tendency is to collect rural data once a year, and to generalise on the basis of conditions observed at that time. As noted above, the time of year when data are collected is crucial - it can even affect estimates of fundamental indicators like poverty headcounts - but all too often the month or season of data collection is not even mentioned in survey reports. It is essential firstly to acknowledge these inherent seasonal biases, and secondly to build a seasonally disaggregated picture of rural livelihoods, with a focus on times of year when rural people are under most stress.

Several methodologies have recently been developed that collect monthly or quarterly data, and explicitly incorporate seasonality into 
an analysis of rural livelihoods, in order to achieve better targeted and better timed interventions. Some of these methods include the following.

- Save the Ghildren UK has developed a methodology to calculate the minimum amount of money a family must spend to meet its nutritional requirements at different times of year. This method, called 'Cost of the Diet', takes into account seasonal variations in food prices and availability (Berton et al. 2009).

- The Livelihoods Integration Unit in Ethiopia has developed the Livelihood Impact Analysis Sheet, building on the Household Economy Approach, which incorporates detailed seasonal calendars and analyses seasonal variations in climate, production, consumption, livelihoods and markets (Boudreau 2009).

- The Jesuit Centre for Theological Reflection (JCTR) in Zambia has devised the 'Rural Basket', a monthly monitoring system that reports on food availability and consumption patterns, cost of food and non-food essentials, as an advocacy tool for interventions during the hungry season (Chibuye 2009).

These methods are typically small-scale rather than national in coverage, implemented by NGOs rather than governments, and not yet integrated into national information systems. The Ethiopian Livelihood Impact Analysis Sheet is an encouraging exception, since data are collected at the local level ('livelihood zones') but analysis and policy responses are incorporated into the national early warning system.

\subsection{Planning for seasonality}

The second step is to incorporate seasonality into the analytical framework of all agricultural projects. How will the project address the range of risks, vulnerabilities and stresses that seasonality creates or exacerbates? How are these risks differentiated across types of people small farmers, landless labourers, pastoralists, local men, women and children? How might project outcomes be affected by seasonality, and how can the project be designed to mitigate the risks that desired outcomes will be compromised by seasonality? Priority issues include:

- What type of seasonality? The adverse effects of seasonality are most often seen in areas where there is one rainy season per year - for example, in the West African Sahel and the Horn of Africa. Here there are sharp peaks in harvested produce and a longer period when rural households face depleted granaries and rely on low-level dry season activities and offfarm employment opportunities. In areas of bimodal rainfall, harvested production and demand for labour are more likely to be spread throughout the year.

- What crops are more or less sensitive? Crops that can be harvested flexibly such as tree products, root crops like cassava, and cereals with a mix of maturity dates are more likely to be seasons-friendly. The practice of mixed cropping allows this flow of product. Lowyielding but drought-resistant crops such as millet provide early relief in the 'hunger season'. Crops with fixed harvesting dates, which includes most cereals, can be associated with seasonal peaks and troughs.

- What market conditions? Seasonality and weak markets reinforce each other, with adverse consequences for the poor. Well functioning markets that smooth food price peaks and allow the easy flow of labour will reduce fluctuations in food availability and consumption, and provide more employment opportunities for those caught in a seasonal 'poverty trap' of high food prices and low wages.

\subsection{Designing for seasonality}

Stabilising income: Agricultural projects should aim to not only raise production and incomes (especially if this implies incurring higher risk) but also stabilise incomes and smooth consumption. Since seasonality introduces damaging fluctuations in the livelihoods and food security of poor rural people, agricultural projects should strive to reduce food insecurity, which means ensuring that subsistence needs are met in a sustainable way, rather than simply raising average yields or incomes. Introducing irrigation for a second cropping season, for instance, is more likely to stabilise food consumption throughout the year than is investing in high-yielding, but highly risky, improved varieties.

'Seasonal-proofing': Drawing on the insights derived from the 'seasonality assessment', project designers and managers should identify what interventions would best mitigate the adverse consequences of seasonality on local lives and 
livelihoods. Depending on the context, this could include developing or extending innovative insurance mechanisms (e.g. weather-indexed crop insurance) to vulnerable farmers, water control systems (e.g. micro-dams or irrigation), or complementary interventions in non-agricultural sectors (e.g. all-weather roads, or accessible, affordable and effective health services).

Professional awareness: Development professionals, agricultural advisers, programme officers and project staff all need to be made aware of seasonality, in each local context where they work. This could be achieved by requiring staff to: (1) take part in baseline surveys or PPAs when seasonal analysis is done; (2) go on village immersions or project visits at the most difficult time of year; and (3) report on seasonal aspects of the project in routine reporting and appraisal activities. More generally, agricultural training and curricula should incorporate seasonality wherever this is absent.

Finally, project proposals should be scrutinised to assess their sensitivity to seasonality before being approved. This would include: (1) whether and how project designers have identified seasonal dimensions of poverty and vulnerability, and how this influenced design; (2) how effectively the project proposes to mitigate or eliminate seasonal risks and vulnerabilities; (3) how seasonal analysis is incorporated in project $\mathrm{M} \& \mathrm{E}$ systems.

\section{Key issues for M\&E}

One reason for limited perceptions about seasonality's impacts is that there are surprisingly few (analysed) datasets that illustrate seasonal trends. Seasonality has profound implications for data collection, analysis and reporting. $\mathrm{M} \& \mathrm{E}$ schedules and project information systems should become more overtly 'seasonal', by disaggregation of data collection and analysis by seasons, reporting on seasonal trends rather than 'averages' at a single point in time, and by examining how resources flow between groups at different times of the year. Since some new variables should be monitored that are not always amenable to quantification, quantitative methods should be combined with qualitative. It is important to link the social and economic position of respondents with the various effects of seasonality, to understand the functioning of 'seasonal poverty traps' better, and their contribution to rural poverty and vulnerability.
In terms of indicators, there is a mesh of factors that revolves around the purchase prices of food, selling prices of food crops, livestock and other assets, and the wages that rural men and women earn with which to buy food and other necessities. These prices vary seasonally, with terms of trade moving against the poor in difficult times of the year. Price data are relatively easy to collect (mainly from local markets), but the arithmetic of assessing their interactions to capture the seasonal perspective might be new. Child malnutrition rates should also be monitored for seasonal impact, but nutrition data are less easy and more expensive to collect on a regular (monthly or quarterly) basis, so proxy indicators might be preferable.

Farmer participation is essential, both in monitoring (to enable real-time feedback and project adjustments around risk indicators) and in evaluation (to test overarching hypotheses for example, have adverse consequences of seasonality been mitigated?) - drawing on both quantitative and participatory methods. Severe 'hungry seasons' are etched in the memories of all rural people, so the simplest approach is still just to ask them and listen to what they say. But the local terminology must be correctly understood: local experiences may diverge from outsider assumptions, even between community members. People from different socioeconomic groups, and different family members, will lose or gain from seasonality to varying extents. Relevant axes of difference include: net food buyers versus surplus food sellers, net labour sellers versus employers of labour, male- versus female-headed households, landed versus landless households. The status of these groups may be assessed during evaluations, using data from baseline and follow-up surveys. There may be other ways of stratifying rural communities that allow the impact of seasonality to be better understood and disaggregated, for purposes of monitoring and evaluation - and learning for improved project design.

\section{Conclusion}

Incorporating a seasonal dimension into $\mathrm{M} \& \mathrm{E}$ does add more complexity to the collection and interpretation of data and information. Data collection must be more frequent, undertaken at times of the year when access to respondents may be difficult, it must be spread across a greater range of rural people, and interactions between 
groups have to be better understood. However, in common with other contributions to this IDS Bulletin, it is argued that this greater complexity is essential for the better functioning of agricultural projects. Specifically, in the case of seasonality, the presence of the 'poverty ratchet' can inhibit many of the poorest rural families being willing to innovate and adopt new practices at any time of the year. For this reason, the awareness of development professionals needs to improve so that no agricultural project is implemented in future that does not have seasonality written into its documentation throughout, from initial conceptualisation to final evaluation.

\section{Note}

* This article is based on a research report prepared for the ALINe project by the authors (Devereux and Longhurst 2010), which examined documents from the African Development Bank (AfDB), the International Fund for Agricultural Development (IFAD)

\section{References}

Berton, H.; Hilton, J. and Taylor, A. (2009) 'Food Affordability: Dealing with Seasonal Variation of Purchasing Power', paper presented at the international conference 'Seasonality Revisited', Brighton: IDS, 8-10 July

Boudreau, T. (2009) 'Livelihoods Impact Analysis and Seasonality in Ethiopia', paper presented at the international conference 'Seasonality Revisited', IDS, Brighton, 8-10 July

Chambers, R. (2009) 'Seasonal Poverty: Integrated, Overlooked and Therefore Opportunity', paper presented at the international conference 'Seasonality Revisited', IDS, Brighton, 8-10 July

Chambers, R.; Longhurst, R. and Pacey, A. (eds) (1981) Seasonal Dimensions to Rural Poverty, London: Frances Pinter

Chibuye, M. (2009) 'Understanding Seasonality Implications on Quality of Life through the Innovative JCTR Rural Basket: The Case of Select Rural Areas of Matushi, Saka and Malama of Zambia', paper presented at the international conference 'Seasonality Revisited', IDS, Brighton, 8-10 July
A final practical point is that this also has important implications for the M\&E process for staff at the sharp end. The enumerators who collect the data from rural people need to be well trained, supported and incentivised: data quality and rapport with rural people depend on it. There is little point in proposing extra complexity in $\mathrm{M} \& \mathrm{E}$ - to bring greater benefits in terms of participation, feedback for learning and better understanding of the dynamics and spread of agricultural projects - if this most important group of people is not adequately supported and recognised.

and the Bill \& Melinda Gates Foundation (BMGF), and was also informed by a study visit to the World Vegetable Centre (AVDRG) in Arusha, Tanzania. Co-funding for this work was provided by the Future Agricultures Consortium.

Dercon, S. and Krishnan, P. (2000) 'Vulnerability, Seasonality and Poverty in Ethiopia', Journal of Development Studies 36.6: 25-53

Devereux, S. (2009) Seasonality and Social Protection in Africa, Growth and Social Protection Working Paper 7, Brighton: Future Agricultures Consortium

Devereux, S. and Longhurst, R. (2010) Seasonality in Agricultural Project Design, Research Report: Agriculture Learning and Impact Network (ALINe), Brighton: IDS

Gill, G. (1991) Seasonality and Agriculture in the Developing World, Cambridge: Cambridge University Press

Jennings, S. and Magrath, J. (2009) 'What Happened to the Seasons?', paper presented at the international conference 'Seasonality Revisited', IDS, Brighton, 8-10 July

Sahn, D. (ed.) (1989) Seasonal Variability in Third World Agriculture, Baltimore: Johns Hopkins University Press

Ulijaszek, S. and Strickland, S. (eds) (1993) Seasonality and Human Ecology, Cambridge: Cambridge University Press 